\title{
Análisis de la participación de las mujeres en el Patrimonio Cultural Inmaterial: procesos de incorporación y visibilización
}

\author{
Itziar Luri Equiza ${ }^{a}$
}

${ }^{a}$ Labrit Patrimonio. C/ Juan de Labrit, 29. 31001. Pamplona - Iruña. itziar@labrit.net

\begin{abstract}
Resumen
Este artículo presenta el resultado del análisis de los procesos y reivindicaciones de las mujeres en cuanto a su incorporación a la parte visible y pública de las manifestaciones inmateriales de la cultura tradicional española. Este estudio tuvo como objetivos concretos la aproximación teórica al Patrimonio Cultural Inmaterial desde una perspectiva de género, el estudio de la representación de las mujeres en los bienes inmateriales declarados BIC en el Estado español y el análisis de la división de funciones determinadas por el género en manifestaciones culturales inmateriales de distintos ámbitos: rituales, manifestaciones festivas y actividades productivas. Además, se realizó una investigación específica de varias manifestaciones culturales inmateriales, con ejemplos de incorporación de las mujeres de manera variada: evolución natural, conflictos en el proceso de incorporación y seguimiento de reivindicaciones en proceso y se concluyó con una propuesta de buenas prácticas para la incorporación de las mujeres a la esfera pública de las manifestaciones culturales inmateriales.
\end{abstract}

Palabras clave: patrimonio cultural inmaterial, género, mujeres, manifestaciones culturales inmateriales, rituales.

\begin{abstract}
This article presents the result of the analysis of women's claims regarding their incorporation into the visible and public part of the intangible manifestations of traditional Spanish culture. This study had as concrete objectives the theoretical approach to the Intangible Cultural Heritage from a gender perspective, the study of the representation of women in intangible items declared BIC in the Spanish State and the analysis of the division of functions determined by gender in Intangible cultural manifestations of different fields: rituals, festive manifestations and productive activities. In addition, a specific investigation of several intangible cultural manifestations was carried out, with examples of incorporation of women in a varied way: natural evolution, conflicts in the process of incorporation and follow-up of claims in process, and concluded with a proposal of good practices for the incorporation of women into the public sphere of intangible cultural items.
\end{abstract}

Keywords: intangible cultural heritage, gender, women, intangible cultural manifestations, rituals. 


\section{Introducción}

El proyecto que se presenta en este artículo fue desarrollado a iniciativa del Instituto del Patrimonio Cultural de España del Ministerio de Cultura y Deporte. María Pía Timón fue la técnica seguidora del proyecto y el equipo de trabajo responsable estuvo integrado por Conchi Cagide Torres (Intangia. Asociación para la defensa de intangibles.), $\mathrm{M}^{\mathrm{a}}$ Ángeles Querol Fernández (Universidad Complutense de Madrid) y Sara González Cambeiro e Itziar Luri Equiza (Labrit Patrimonio).

Las manifestaciones del patrimonio cultural inmaterial portan y transmiten conocimientos y normas relacionadas con las funciones y relaciones entre los distintos géneros de una determinada sociedad, puesto que los valores relacionados con el género varían entre las distintas sociedades, comunidades y grupos. De ahí que el patrimonio cultural inmaterial constituya un contexto idóneo para la conformación y transmisión de las funciones e identidades de género, pudiendo determinar que el patrimonio cultural inmaterial y la construcción propia de la identidad de género son, por tanto, inseparables.

Cuando analizamos los fenómenos o manifestaciones culturales a las que consideramos PCI, nos situamos en un ámbito definido por la "tradición" que pretende colocarse en un momento anterior a la modernidad, un momento en el que los roles de género -de los dos géneros tradicionales- estaban asumidos, impuestos y aparentemente inmutables. Sin embargo, ese PCI que analizamos vive en el presente -y por eso lo podemos salvaguardar- de forma que los cambios que supone la modernidad han de afectarle de alguna manera. Hay por lo tanto un curioso fenómeno de tira y afloja. El PCI vive o sobrevive en medio de una tormenta en la que, por una parte, la tradición (inmutable) juega un importante papel y por otra -y en occidente- la modernidad (mutable) se impone tal y como lo hace en cualquier otra manifestación humana no tradicional.

El PCI, al reconocer como ámbitos de manifestación de los bienes culturales esferas tales como la alimentación, las técnicas artesanales o una dimensión más privada de los rituales y creencias, revitaliza la representatividad que el quehacer femenino ha tenido y tiene en el ámbito de la tradición cultural española. Dota así de visibilidad y valor a una esfera de la trayectoria vital de las comunidades y grupos que, por la cotidianeidad inherente a la misma, no ha sido considerada digna de estudio y valoración pública, asignando por extensión a sus protagonistas, las mujeres, el valor y singularidad que les corresponde.

Las mujeres, como miembros de pleno derecho de las comunidades portadoras del PCI, miembros que siempre han participado tanto de las actividades de transformación como de las festividades, rituales y organizaciones desde la invisibilidad que generan los preparativos e infraestructura cotidiana, están comenzando a reclamar su presencia activa y visible en las mismas. Ellas, como portadoras de la tradición, están reivindicando el lugar que consideran legítimo en el desarrollo de las manifestaciones propias de la cultura española, de las que se sienten tan titulares como los hombres, por lo que la acción de los poderes públicos al facilitar el acceso y trasmisión de dicho Patrimonio habrá de redundar de forma positiva, sin condicionar el cambio más allá de lo consensuado por las comunidades, en la presencia igualmente activa y representativa de ambos géneros en los bienes culturales inmateriales.

\section{Metodología y resultados}

De acuerdo con todo lo anterior, el estudio se centró en visibilizar y analizar los procesos y reivindicaciones de las mujeres en cuanto a su incorporación a la parte visible y pública de las manifestaciones inmateriales de la cultura tradicional española. Se estudiaron estos procesos desde un punto de vista teórico, legislativo y también a través del trabajo de campo.

\subsection{Análisis del rol de las mujeres en los bienes inmateriales declarados BIC}

A lo largo del estudio se analizaron una serie de expedientes de declaración de Bien de Interés Cultural, que organizamos a través de ciertos aspectos llamativos de la relación entre mujeres y PCI. 
- Mujeres y artesanías. Como se ha comentado, el rol de las mujeres en el PCI depende a menudo de los ámbitos en los que se manifiesta. Por ejemplo, las mujeres tienden a ser más protagonista en manifestaciones relacionadas con el ámbito privado o el trabajo manual, como en las artesanías, y menos protagonistas en rituales públicos, especialmente los considerados en el siglo XX más complejos, arriesgados o espectaculares.

- Mujeres y sacrificio. Además de las dificultades añadidas para la incorporación al PCI, que ocurren en la práctica en la incorporación a otros muchos ámbitos de la vida y la sociedad, es llamativo cómo en el PCI las mujeres son seres sufrientes y que transportan pesadas cargas, físicas y simbólicas.

- Trato denigrante o discriminatorio. Entre otros, naturalización de los 'piropos', que perpetúan relaciones de desigualdad.

- Papeles femeninos interpretados por hombres. Fundamentalmente en manifestaciones religiosas pero no solo en ellas.

- La belleza y la bondad. Además del sacrificio personal, la generosidad y otra serie de valores que a menudo han complicado la vida de las mujeres, en el Patrimonio Inmaterial se deposita, también, la responsabilidad sobre la bondad del mundo en ellas. Además, la colocación de las mujeres en el escaparate social simplemente con la intención de lucir su belleza ha impedido a menudo su acceso a lugares donde lo valorado era el intelecto y no lo físico.

- Adaptación a los nuevos tiempos. Quisimos cerrar este análisis, pesimista en ocasiones, con una muestra de la capacidad de adaptación del PCI a la nueva sensibilidad hacia la igualdad que afortunadamente comenzamos a vislumbrar.

\subsection{Determinación de los ámbitos de incidencia prioritarios para los/las agentes socioeconómicos}

De acuerdo con el proyecto presentado, la segunda fase consistió en una serie de trabajos de campo destinados a analizar in situ los procesos de incorporación de las mujeres a las manifestaciones culturales inmateriales seleccionadas. Se han realizado entrevistas tanto a personas como a grupos, de ambos sexos, con el fin de documentar al máximo la historia, los posibles problemas y los resultados de las iniciativas de incorporación. Se escogieron manifestaciones en las que, al menos en un principio, no participaban las mujeres, teniendo muy en cuenta las variables de carácter cronológico, social, económico y medioambiental. Se estructuró el análisis en tres bloques, y en cada uno de ellos se analizaron tres casos. Vamos a resumir a continuación los ejemplos estudiados:

\subsubsection{Manifestaciones culturales inmateriales donde la incorporación de las mujeres a la esfera pública se haya realizado de manera natural.}

- Festa de la Mare de Déu de la Salut de Algemesí (Valencia). El paso de la Virgen va precedido por una larga secuencia de grupos que representan o bailan. En su origen bailaban niñas, pero no adultas. A partir de 1900 comienzan a bailar las adultas y desde 1977 la música es interpretada tanto por hombres como por mujeres. La muixeranga -origen de los castells catalanes- es la más interesante para nuestro estudio: siempre fueron hombres, pero en 1997 se crea la llamada Nueva Muixeranga, en la que había mujeres. Y a partir de ahí las hay tanto en la nueva como en la vieja.

- Danzas de Belinchón (Cuenca). Son danzas que el porra o botarga, el castañuelón y ocho danzantes ejecutan en las fiestas del Santo Cristo Arrodillado. Siempre fueron hombres: a mediados de los 80 algunas mujeres se empeñaron en danzar. Ahora son más, "lo hacen mejor" según nuestras informantes y transmiten su conocimiento. Además, las mujeres transformaron la connotación negativa de la fiesta.

- Misteri d'Elx (Alicante). Es la representación sacra medieval que se celebra los días 14 y 15 de agosto de cada año en el interior de la basílica. Además, existen otras actividades en torno a ella: la nit del alba, la nit de la roa, preparación de imágenes, sastrería, etc. En esta segunda parte las mujeres han participado siempre. A finales del pasado siglo comienzan a incorporarse mujeres en la parte menos visible; no así en la de los niños cantores, que asumen los papeles femeninos. Aunque algunas voces protestan, por lo general se asume que en los próximos años, "la voluntad de las niñas que quieran hacer de Virgen y de Marías, se impondrá sin problemas". 


\subsubsection{Manifestaciones culturales inmateriales donde la incorporación de las mujeres a la esfera pública haya supuesto} un conflicto o tensión social.

- Alardes del Bidasoa (Gipuzkoa). En el País Vasco y desde la Edad Media cada pueblo tenía su milicia foral, a la que pertenecían todos los varones entre 18 y 60 años. En las épocas de asedio, la seguridad dependía de esta milicia urbana. A pesar de que los alardes se han modificado en el último siglo en multitud de aspectos, los grupos contrarios a la igualdad siguen utilizando 'la tradición' como algo inmutable. Las mujeres habían participado en los alardes como preparadoras de la indumentaria y comida o bien en la figura de cantineras. Las cantineras representan un papel fundamentalmente "expositivo“. Actualmente existen en Irún dos alardes 'privados' (aunque uno de ellos tiene de su lado al alcalde de la ciudad). El Ayuntamiento de Hondarribia privatizó el Alarde y la Compañía Jaizkibel sigue sufriendo situaciones muy violentas cada 8 de septiembre que intenta desfilar. Nuestra informante afirmaba que "las personas con poder están por encima de la legalidad".

- Fiesta del voto de Santa Ana en Santa Ana la Real (Huelva). Los principales agentes son 4 diputados cada año, que recogen donativos, conducen al toro y además eligen a los 4 diputados del año siguiente. En 2003 uno de los diputados eligió a una mujer y el pueblo se dividió. Se les convocó a una votación y salió en contra de la mujer, que se retiró no sin antes dejar por escrito su queja ante distintas instancias. La defensoría del pueblo andaluz le dio la razón, pero el conflicto no se ha solucionado y las mujeres no participan como diputadas.

- Lucha Leonesa (León). Es un combate entre dos contendientes que, agarrados con las dos manos al cinto, y mediante la utilización de estrategias conocidas como mañas, luchan por derribar al contrincante y llevarle al suelo. Se reglamentó y se organizaron campeonatos a partir de 1931. En los 80 irrumpieron "las niñas luchadoras" en las categorías infantiles y juveniles. Hasta el año 2006 no comenzaron a conseguir formar grupos senior de lucha femenina, creando el colectivo "Nosotras luchamos". Llegaron a ser bastantes, pero el número disminuye en la actualidad por falta de apoyo público y privado.

\subsubsection{Manifestaciones culturales inmateriales donde la incorporación de las mujeres a la esfera pública se esté} desarrollando a través de un proceso específico de sensibilización y participación.

- Bolantes de Valcarlos (Navarra). Históricamente las danzas de Bolantes en Luzaide/Valcarlos formaban parte del ciclo de Carnaval. Actualmente el Día de los Bolantes se celebra el Domingo de Resurrección. En los años 60 comienzan a participar mujeres en las danzas sociales mixtas. En 1968 se diseñan sus trajes y adornos. En 2016 se organizó un referéndum para ver qué opinaba el pueblo sobre que las mujeres bailaran los jauzis y qué ropa debían llevar. El 75\% se manifestó a favor de que bailaran y que lo hicieran con los trajes actuales.

- Sociedades Gastronómicas (País Vasco). En muchas de estas sociedades, en sus estatutos se observa una discriminación directa (solo varones). En otras no se dice nada de esto, pero se ponen condiciones de difícil cumplimiento para las mujeres, como ser presentadas por dos socios (discriminación indirecta). Fue objeto de mediación de las Administraciones Públicas: la ley vasca 4/2005 para la igualdad de mujeres y hombres, dice "se prohíbe la organización y realización de actividades culturales en espacios públicos en las que no se permita o se obstaculice la participación de las mujeres en condiciones de igualdad con los hombres". Si no se cumple, no tendrán derecho a subvenciones o ayudas, serán sancionadas y además se les podrá denegar o anular su inscripción oficial como asociación. No obstante, sigue habiendo quejas de mujeres a las que se les impide la participación en igualdad.

- Cofradías de Semana Santa (Sevilla). En 2011 y a petición de las mujeres, el Arzobispo de Sevilla publicó un Decreto sobre "La plena igualdad de derechos" entre hombres y mujeres en las manifestaciones externas de culto. Esto obligó a las hermandades, quisieran o no, a permitir la salida de las mujeres como nazarenas. En aquellos momentos las mujeres ya habían conquistado terrenos y solo quedaban algunas cofradías en las que no se autorizaba a las mujeres a procesionar. En cuanto a ser costaleras, resulta mucho más difícil, y la informante señaló la existencia de algunas cuadrillas costaleras compuestas solo por mujeres. Su número sigue siendo minoritario y siguen encontrando dificultades. 


\section{Propuesta de Buenas Prácticas}

A la luz de las conclusiones del estudio, se realizó una propuesta de Buenas Prácticas para la incorporación de las mujeres a las manifestaciones del Patrimonio Cultural Inmaterial.

1. La educación en igualdad -tanto la formal como la informal- es fundamental para convencer a las mujeres, desde la infancia, de que pueden y deben ocupar los mismos puestos y desempeñar los mismos roles de los hombres. Este tipo de educación es fundamental también para otros muchos aspectos de la vida, para casi todos, por lo que resulta ser una buena práctica transversal.

2. Incorporación o aprendizaje desde la infancia: si por ejemplo las niñas de Elche aprenden la música del Misteri desde su infancia, al igual que hacen los niños, seguro que llegará un momento en que pidan actuar igual que sus hermanos. Si en las danzas guerreras o masculinas las niñas comienzan ya a formar parte de los grupos de danzantes, ayudándoles, aprenderán a bailar y exigirán hacerlo en un próximo futuro. Y un largo etc.

3. Una gran ayuda es la difusión de experiencias de éxito en situaciones diversas, de modo que mujeres que están luchando por integrarse vean que resulta posible hacerlo.

4. Para casos de gran dificultad, como algunos de los que hemos revisado, las líneas a seguir pasan sobre todo por la mediación, una herramienta que funciona ya en el ámbito intercultural, como medio eficaz de acercamiento entre partes enfrentadas en un conflicto social. También es interesante el recurso al referéndum o votaciones entre personas que se sientan identificadas o interesadas en la manifestación; en definitiva, la participación ciudadana.

\section{Balance y conclusiones}

Para concluir, debemos recordar nuestro punto de partida: las manifestaciones culturales inmateriales son entes vivos que están en continuo proceso de cambio. A veces esos cambios se producen por cuestiones económicas, otras veces por deseos de mejora, por rivalidades o por intrusismo. Y otras veces, que son las que estamos analizando, por la presión social de una parte de la ciudadanía, en este caso, de las mujeres. No nos parece admisible la opinión de que las tradiciones "han de seguir siendo iguales" cuando es evidente que ha habido cambios, que los hay y que los seguirá habiendo mientras esa manifestación viva. Cuando deje de cambiar, habrá muerto y desaparecido. Como es lógico, la principal conclusión a la que podemos llegar en este trabajo es la de constatar que en las manifestaciones que hemos analizado, en su mayor parte de carácter festivo, el machismo ha sido la tónica por lo que respecta a la visibilidad y la participación protagonista. Este dato no es indicativo de ninguna característica especial, ya que se ha dado en la sociedad occidental judeo-cristiana desde hace unos 4000 años de forma documentada. Lo verdaderamente importante, en este caso, es constatar que incluso dentro de las tradiciones más evidentes las mujeres han intentado entrar y lo han conseguido en muchos casos, a partir sobre todo del último tercio del siglo XX.

Nos situamos pues en un punto del tiempo que no es el inicial, ya que han pasado casi 40 años desde los 80 , la fecha más repetida para el inicio de los cambios en este estudio, pero tampoco de ninguna manera conclusivo. En este punto intermedio en que nos encontramos la característica principal parece ser la variedad: tradiciones que luchan por "seguir siendo masculinas", pueblos enteros que votan a favor o en contra de la participación femenina, introducciones casi solapadas y silenciosas, decretos emitidos desde lo más alto que sirven para acallar protestas...

Está claro que queda mucho por hacer, y que en esta cuestión la propia voluntad de las mujeres, junto con la existencia de normas que la favorecen, son los dos activos principales con los que contamos para seguir adelante. 